\title{
Effect of iron supplementation during infancy period
}

\author{
S. Songül Yalçın
}

Department of Pediatrics, Hacettepe University Faculty of Medicine, Ankara, Turkey. E-mail: siyalcin@hacettepe.edu.tr Received: 7th September 2018, Accepted: 25th January 2019

\section{To the Editor,}

I read with great interest the article by Çullas-İlarslan et al. ${ }^{1}$ entitled "Investigation of the frequency of iron insufficiency among infants in a population in which routine iron supplementation (IS) is implemented". However, I think that some points should be discussed.

The article is based on an institutional and not a community based study. Being a hospital-based study from an outpatient clinic, the results could not be generalized to the population and it gives limited local data on iron status. On the other hand, the frequency of wasted children in the article was found higher (4.0$7.1 \%)$ than national data. The Demographic Health Survey-2013 reported wasted prevalence as $1.1 \%$ for infants aged 9-17 months and $1.4 \%$ for normal-birth weight children under 5 years of age in Turkey. ${ }^{2}$ However, wasting as a confounding factor was not taken in multivariate analysis of the present study.

In Turkey, only two surveys had representative data for anemia during infancy period, however, different age groups (12-24 months and 6-17 months of age) and different anemia definitions [cut-off value of hemoglobin ( $\mathrm{Hb})$ and ferritin] were used. ${ }^{3,4}$ The first study was carried out in 2006-2007 covering three NUTS (Nomenclature of Territorial Units for Statistics) regions with low, middle and high health indicators. ${ }^{3}$ In that survey iron supplementation (IS) had been given to $68.8 \%$ of children. During this survey, mostly ferrous iron had been given for prophylaxis. The prevalence of anemia (defined as $\mathrm{Hb}<11.0 \mathrm{~g} / \mathrm{dl}$, ferritin cut-off point, $<15$ $\mu \mathrm{g} / \mathrm{L})$ was $7.3 \%$ in infants $(\mathrm{n}=2300)$ aged 12 24 months $(10.5 \%$ for children $<15$ months of age and $6.9 \%$ for children from 15 to 17.9 months of age). Multivariate analysis of that survey demonstrated higher frequency of anemia in infants with younger age, shorter duration of breastfeeding ( $<6$ months), IS starting at a later age ( $\geq 9$ months), crowded family ( $\geq 6$ persons), absence of maternal IS during pregnancy and maternal history of iron deficiency anemia (IDA). ${ }^{3}$ The second study, which took place in 2011 , showed that $21.8 \%$ of infants aged $6-18$ months had anemia $(\mathrm{Hb}<10.5 \mathrm{~g} / \mathrm{dl}), 28.7 \%$ iron deficient (ferritin $<10.0 \mu \mathrm{g} / \mathrm{L})^{4}$, however, only $6.3 \%$ had IDA. When the West Anatolia including Ankara were evaluated from that survey, iron deficiency was detected to be $27.5 \%$ and IDA $6.3 \%$.

Previous studies evaluated gender effect on the frequency of IDA for different age groups. 5,6 Similar to the present study, a previous study detected lower $\mathrm{Hb}$, mean corpuscular volume and higher red cell distribution width values in boys aged 5-7 months in a group who had received no IS previously, and who were exclusively breastfed for at least four months. At the same time, higher postnatal growth gain in boys than girls $(799 \pm 133,740 \pm 125$ $\mathrm{g} /$ month, from birth to 5-7 months of age; $\mathrm{p}<0.001$ ) was demonstrated and might have had a role in the differences. ${ }^{6}$

Type of iron preparation given might be one factor in the differences in the frequencies of IDA. Aydin et al. ${ }^{7}$ enrolled healthy-term infants who were exclusively breastfed for an intervention study, gave IS starting at 4 months of age, for 5 months and detected the prevalence of IDA $(\mathrm{Hb}<11 \mathrm{~g} / \mathrm{dL}$ and transferin saturation $<16)$ was $8.9 \%$ in the ferrous prophylaxis group and $21.4 \%$ in the ferric iron prophylaxis group at 9 months of age and in the present study all cases had recieved ferric iron.

Interactions among maternal life-long history of IDA, iron status and compliance to IS might have a role on ID and IDA of infants. Giving IS to nonanemic mothers during the first four months of the lactation period had no effect on the serum iron and ferritin levels of mothers and infants. ${ }^{8}$ However, Zhang et al. ${ }^{9}$ reported that infants born to women with mild anemia $(\mathrm{Hb}=10.0-10.9 \mathrm{~g} / \mathrm{dl})$ at the end of the second trimester had almost double the 
risk of overt anemia at 5-7 and 11-13 months of age, compared with infants born to women with $\mathrm{Hb} \geq 11 \mathrm{~g} / \mathrm{dl}$. In the present study, the parameters did not include maternal age and maternal compliance to iron supplementation as a limiting factor.

Despite no significance in multiple logistic analysis in the present article, authors discussed longer breastfeeding (still breastfeeding infants aged 9-15 months) as a risk for IDA. International health agencies such as the World Health Organization and UNICEF recommend exclusive breast-feeding up to 6 months and continued breastfeeding for at least 2 years. ${ }^{10}$ Appropriate and timely initiation (at 6 months of age) of complementary feeding is necessary for prevention of nutritional deficiencies. Longterm breastfeeding was reported not to affect the consumption of appropriate complementary food. ${ }^{11}$

In the present study, minimum starting age for IS was 4 months of age as in the "Ironlike Turkey project", however, duration of IS was grouped as $<4,4.0-7.9$ and $\geq 8$ months in statistical comparisons. It is impossible to have a history of IS $\geq 8$ months for enrolled infants aged 9-12 months in the present study. Explanation of these concerns will certainly provide clearer information for the readers.

Key words: maternal anemia, iron supplementation, infant anemia.

\section{REFERENCES}

1. Çullas-İlarslan NE, Günay F, İleri DT, Elhan AH, Ertem $\mathrm{M}$, Arsan S. Investigation of the frequency of iron insufficiency among infants in a population in which routine iron supplementation is implemented. Turk J Pediatr 2018; 60: 22-31.
2. Hacettepe University Institute of Population Studies. 2013 Turkey Demographic Health Survey. Hacettepe University Institute of Population Studies, Republic of Turkey Ministry of Development and TUBITAK, Ankara: 2014.

3. Yalçın SS, Tezel B, Yurdakök K, et al. A communitybased iron supplementation program, "Ironlike Turkey", and the following prevalence of anemia among infants aged 12-23 months. Turk J Pediatr 2013; 55: 16-28.

4. Türkiye'de 6-17 Aylık Çocuklarda ve Annelerinde Hemoglobin Ferritin D -Vitamini Düzeyi ve Demir Eksikliği Anemisi Durum Belirleme. Yürütülen Programların Değerlendirilmesi Araştırması. Ankara: Gazi Üniversitesi/Sağlık Bakanlığı; 2011.

5. Wieringa FT, Berger J, Dijkhuizen MA, et al. Sex differences in prevalence of anaemia and iron deficiency in infancy in a large multi-country trial in South-East Asia. Br J Nutr 2007; 98:1070-1076.

6. Yalçin SS, Dut R, Yurdakök K, Özmert E. Seasonal and gender differences in hemoglobin value in infants at 5-7 months of age. Turk J Pediatr. 2009; 51: 572-577.

7. Aydin A, Gur E, Erener-Ercan T, Can G, Arvas A. Comparison of Different Iron Preparations in the Prophylaxis of Iron-deficiency Anemia. J Pediatr Hematol Oncol 2017; 39: 495-499.

8. Baykan A, Yalçin SS, Yurdakok K. Does Maternal Iron Supplementation During Lactation Period Affect Iron Status of Exclusively Breast-Fed Infants? Turk J Pediatr 2006; 48: 301-307.

9. Zhang Y, Jin L, Liu J-m, Ye R, Ren A. Maternal hemoglobin concentration during gestation and risk of anemia in infancy: secondary analysis of a randomized controlled trial. J Pediatr 2016; 175: 106-110.

10. World Health Organization, UNICEF. Global Nutrition Monitoring Framework: Operational Guidance For Tracking Progress In Meeting Targets For 2025. Geneva: World Health Organization; 2017.

11. Yalçın SS, Yalçın S, Kurtuluş-Yiğit E. Determinants of continued breastfeeding beyond 12 months in Turkey: secondary data analysis of the Demographic and Health Survey. Turk J Pediatr 2014; 56: 581-591.

\title{
Response to "Effect of iron supplementation during infancy period"
}

\author{
Nisa Eda Çullas-İlarslan \\ Department of Pediatrics, Ankara University School of Medicine, Ankara, Turkey E-mail: md.eda@hotmail.com
}

To the editor,

We thank for the concerns listed in the "Letter to the Editor" which was sent for our original article entitled "Investigation of the frequency of iron insufficiency among infants in a population in which routine iron supplementation (IS) is implemented", published in the Turkish Journal of Pediatrics. ${ }^{1}$ Below you will find our replies to these comments.

One concern was mentioned as a limitation 
of this study as this hospital-based data could not be generalized to a population. We have listed this limitation in the discussion section. ("Including infants from one NUTS-1 region is the first limitation"). We hope that our study will be followed by a recent population-based study.

It was also stated that although wasted prevalence was found higher than the national data in our series, it was not included as a confounding factor in multivariate analysis. ${ }^{2}$ Actually, we did not include this factor in our multivariate analysis as wasted prevalence of iron sufficient and iron insufficient infants was similar.

Another concern focused on different anemia definitions during infancy used in different studies. We used cut-off levels which were defined by World Health Organization (WHO) for infants aged 6-24 months. ${ }^{3}$ These cut-off values were also used by Yalcin et al., who carried out the most comprehensive clinical trial in Turkey investigating the prevalence of IDA in infants following national iron supplementation. ${ }^{4}$

Another concern listed in the letter to the editor was type of iron preparation given to the infants included in our study. We believe that use of ferric instead of ferrous iron might have contributed to a higher rate of iron insufficiency encountered in our study, when compared with Yalcin et al.'s study. ${ }^{4}$ On the other hand, we observed lower rate of iron insufficiency in infants who were compliant, indicating that compliance seems to have more impact on iron insufficiency.

Absence of maternal age and maternal compliance to iron supplementation in our analysis was reported as an additional concern. Although we included maternal iron supplementation and maternal iron deficiency anemia (IDA) to our analysis, we believe that inclusion of maternal compliance to iron might have provided better understanding of the effect of maternal iron status on iron insufficiency of infants.

It was also denoted in the letter to the editor that longer breastfeeding was mentioned as a risk factor in our study. Actually, we did not signify longer breastfeeding as a risk factor for iron insufficiency. Inversely, we aimed to emphasize the importance of iron supplementation along with continued breastfeeding following 4-6 months of age. The letter also included a statement indicating that long-term breastfeeding does not affect the consumption of appropriate complementary food. We truly agree, and would like to clarify that this issue of concern was not accepted as a contributing factor to iron insufficiency in our cohort. Repeatedly, our goal was to delineate the necessity of iron supplementation in infancy in addition to iron received from breastfeeding and complementary food.

The duration of iron supplementation was another concern of the letter to the editor. We divided the duration of iron use into three groups ( $<4,4.0-7.9$ and $\geq 8$ months). As we included infants between 9-15 months, infants who continued to receive iron after 12 months of age were included in the last category, reflecting use of iron for a period of $\geq 8$ months.

Although our findings may not be generalized as Turkey's national data, we strongly believe that it reflects importance as it demonstrates a high frequency of IDA in infants who apply to a university hospital in Ankara. We believe that this finding also indicates the existence of some difficulties in the implementation of a very valuable project called "Iron-like Turkey", which suggests iron supplementation to all infants since 2004 . Henceforth, we aim to evaluate the reasons of IDA in infants in more detail.

\section{REFERENCES}

1. Çullas-İlarslan NE, Günay F, İleri DT, Elhan AH, Ertem $M$, Arsan S. Investigation of the frequency of iron insufficiency among infants in a population in which routine iron supplementation is implemented. Turk J Pediatr 2018; 60: 22-31.

2. Hacettepe University Institute of Population Studies. 2013 Turkey Demographic Health Survey. Hacettepe University Institute of Population Studies, Republic of Turkey Ministry of Development and TUBITAK, Ankara: 2014.

3. World Health Organization. Iron deficiency anaemia. Assessment, prevention and control. A guide for programme managers. World Health Organization, 2001. Available at: http://www.who.int/vmnis/anaemia (Accessed January 20, 2016).

4. Yalçın SS, Tezel B, Yurdakök K, et al. A communitybased iron supplementation program, "Ironlike Turkey", and the following prevalence of anemia among infants aged 12-23 months. Turk J Pediatr 2013; 55: 16-28. 